\section{New Findings in the Field of lonic Liquids}

Professor Udo Kragl, a chemist from the University of Rostock, will shortly be awarded a research prize by the German Federal Ministry of Education and Research (BMBF) as part of the Biotechnology 2020+ strategy process for his innovative methods of combining ionic liquids and biocatalysis. Ionic liquids could also play a role in the production of new types of adhesives.
E or many years, biocatalysis has been - used in the manufacturing of fine chemicals and pharmaceutical building blocks because of its selective and efficient reaction conditions. However, new applications for ionic liquids, a new class of solvents, have only been developed in the last decade," explains Professor Kragl, holder of the chair of technical chemistry and dean of the interdisciplinary faculty at the University of Rostock. Their special properties make it possible for particular combinations of substances to be dissolved in them. This enables the liquids to be used, for example, for stabilising enzymes as biocatalysts or as selective agents for extracting biomolecules. There is an almost unlimited number of applications for ionic liquids, which include, for example, splitting cellulose, improving lubricants and the production of new types of adhesives and medical products.

The prize is accompanied by project sponsorship of 1.8 million euros over the next five years.

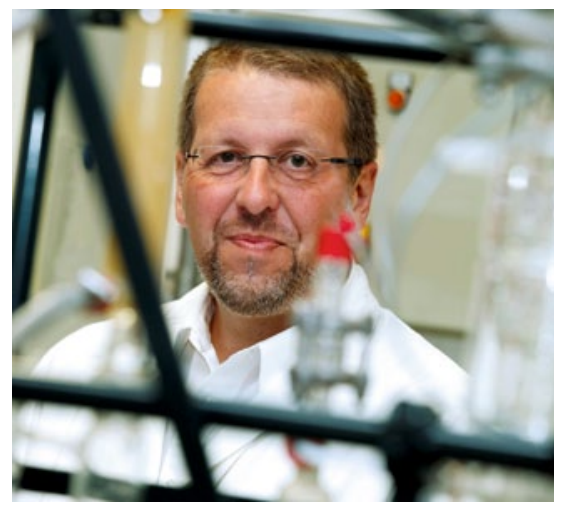

Professor Kragl, holder of the chair of technical chemistry and dean of the interdisciplinary faculty at the University of Rostock

\section{New Management Structure}

$\triangle$ short time after expanding its long-term partnership with Huntsman AdVomie Switzerland AG has made some changes to its management structure. With immediate effect, Frank Haug becomes the new CEO, while Andreas Baettig and Jürgen Ihrybauer become managing directors, taking responsibility for the tasks of the administrative council (delegates). Having taken over the sales operations of the products manufactured by Huntsman Advanced Materials, Bodo Möller Chemie Schweiz AG is now the main distributor for Araldite adhesives and Araldite casting resins and laminate resins in the region. Customers in the Swiss region can now be comprehensively supplied with, among other products, professional adhesive systems based on epoxy resins, polyurethanes or methacrylates, casting resins and compounds for the electronics industry as well as modelling products and laminate resins. In addition to Huntsman's adhesives products, Bodo Möller Chemie Switzerland AG has a product portfolio consisting of different international companies such as Dow Automotive Systems, Henkel and other manufacturers.

For further information, please visit: www.bm-chemie.det

\section{Pre-treatment}

\section{Deburring}

Washing

Degreasing

Cleaning

Analysing

Monitoring

\section{What do}

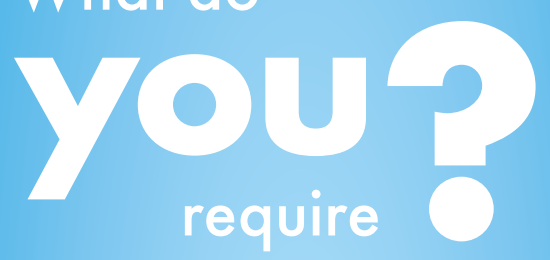

\section{Quality needs perfection.}

Leading International Trade Fair for Industrial Parts and Surface Cleaning

22 to 24 October 2013 Stuttgart - Germany 